\title{
Model of Maximum CBR Distance Travelled by packets in MANETs using Location-Aware Transmission for Ubicomp.
}

\author{
M. Kaleem GALAMALI, Assoc. Prof Nawaz MOHAMUDALLY
}

\begin{abstract}
MANET transmission strategies in MANET are considered good for energy containment and management for ubicomp [62]. Hence research in location-awareness and MANETs remain very significant. It is projected that further development will involve technologies like landbased GPS systems, improved location refresh rates and location accuracy, along with developments of better protocols optimised for transmission following distance criteria. To better tune transmission protocols and achieve optimal MANET performance, one desirable knowledge would be the trends of distance coverages by packets in a ubicomp for varying node densities.
\end{abstract}

A previous study in this direction was made [26], whereby the metric PPD was devised. In this paper, another metric "Max_CBR_Dist", derived from PPD is defined and its corresponding trends over varying node densities are presented.

This paper adds a second component after the metric PPD [26] to the area of modelling for managing distance packets travel in ubicomp topography of varying node densities. Designers may use these results towards formulation of better transmission protocols for ubicomp. This research is a follow-up of previous work [1-26].

Key terms: Ubicomp- Ubiquitous Computing, MAUCMobile and Ubiquitous Computing, MANET- Mobile Adhoc Network, PPD- Packets_Per_Distance, Max_CBR_Dist - Maximum_CBR_Distance, CBRConstant Bit Rate.

M. Kaleem GALAMALI,

University of Technology Mauritius (student) Mauritius

Assoc. Prof Nawaz Mohamudally University of Technology Mauritius, Mauritius

\section{Introduction}

Distance coverage is a predominant factor affecting energy consumption in MAUC. This energy expenditure varies proportional to the square of distance a packet travels [15]. In MANET transmission, the sender node along with all MANET route nodes forward packets corresponding to each CBR. One impact in the topography is that total number of packets circulating within the MANET topography. With increasing node density, this total number of packets is expected to increase. The sender node forwards packets to the closest neighbour but there is no guarantee that all hops will be of equal distance nor that the first hop is the smallest or biggest one for each CBR. The research questions put forward here are: "What are the maximum hop distance experienced by each CBR? What is the trend observable for this maximum hop count and how does it vary with varying node densities?"

The work presented here, is also empirical based and is built over previous work [26]. It follows from the statement that metric PPD remains a wide scope metric from which other sub-component metrics could be formulated. Each such sub-component metric may have specific characteristics that may be utilised for specific decision making in protocols to be used.

The key contributions of this paper is firstly, the development of a derived metric Max_CBR_Dist, derived from PPD for CBR Packet Per Distance analyses. The definition and rationale of metric Max_CBR_Dist is put forward. Secondly, the model of trend is put forward for the metric Max_CBR_Dist with results for varying node densities from 7 until 56 in a topography of $300 \times 300 \mathrm{~m}^{2}$. The model proposed is the normal distribution model. The rest of this paper is organised as follows: section 2- New Derived Metric Maximum_CBR_Distance, section 3- Max_CBR_Dist Trend Assessment over Varying Node Numbers, 4Conclusion and References.

\section{New Derived Metric - Maximum_CBR_Distance.}

Following definition of PPD [26], Max_CBR_Dist is defined as the maximum distance coverage noted for the whole of a CBR along a MANET topography. It can also be termed as the longest hop distance noted for a CBR.

MANET routes may vary during a CBR transmission. It is envisageable to have the metric at value 0 . This may occur for short durations of transmission with snapshot MANET topology whereby all hops are below $0.5 \mathrm{~m}$ even though distance between sender and receiver may be high.

The results of this study may serve towards the same purposes as described in previous paper [26]. 
Proc. of Sixth International Conference On Advances in Computing, Electronics and Electrical Technology - CEET 2016 Copyright (C) Institute of Research Engineers and Doctors. All rights reserved.

ISBN no. 978-1-63248-109-2 doi: 10.15224/ 978-1-63248-109-2-09

\section{Max_CBR_Dist - Trend Assessment over Varying Node Numbers.}

\subsection{Major Observations.}

For most of the plots from node numbers 7 until 56, the least value of Max_CBR_Dist has revolved around 21.

The plots are very scattered but as depicted in figure 1(a) for node number 7, the plausible "S" shape of the normal distribution is clearly visible. Hence it is put forward that the metric Max_CBR_Dist follows normal distribution with equation of the form:

$F(x)=b *(1 /(a * \operatorname{sqrt}(2 * p i))) * \exp (-(x-c) *(x-c) / 2 * a * a)$

It can also be read as $\mathrm{F}(\mathrm{x})$ equals to a factor (b) times the equation of a normal curve.

The $\mathrm{x}$-coordinate of the peak values tend to increase with increasing node number.

\subsection{Tabular Summary of Results.}

A tabular summary for results of equations of curves $(\mathrm{F}(\mathrm{x}))$ is shown below. Column headings are: $\mathrm{A} \rightarrow$ node number, $\mathrm{B} \rightarrow$ Value of parameter $\mathrm{a}, \mathrm{C} \rightarrow$ Value of parameter $\mathrm{b}, \mathrm{D} \rightarrow$ value of parameter $\mathrm{c}$ (the adjusted mean), $\mathrm{E} \rightarrow$ reduced chi-square value of plot $\mathrm{F}(\mathrm{x}), \mathrm{F} \rightarrow$ Corresponding figure number.

\begin{tabular}{|c|c|c|c|c|c|}
\hline A & B & C & D & $\mathbf{E}$ & F \\
\hline 7 & 0.0164389 & 0.0282321 & 205.829 & 0.0484091 & 1(b) \\
\hline 8 & 0.0163904 & 0.0280905 & 205.653 & 0.0484553 & 2 \\
\hline 9 & 0.0161677 & 0.0273075 & 207.217 & 0.0447133 & 3 \\
\hline 10 & 0.0172183 & 0.0304113 & 211.3 & 0.043087 & 4 \\
\hline 11 & 0.0174109 & 0.0308802 & 231.38 & 0.0410077 & 5 \\
\hline 12 & 0.0165666 & 0.0285023 & 27.001 & 0.047092 & 6 \\
\hline 13 & 0.0175925 & 0.0311315 & 219.341 & 0.0369615 & 7 \\
\hline 14 & 0.0185591 & 0.0340215 & 222.619 & 0.0327101 & 8 \\
\hline 15 & 0.0179987 & 0.0324347 & 225.176 & 0.0403142 & 9 \\
\hline 16 & 0.0175 & 0.0305823 & 226.394 & 0.0421065 & 10 \\
\hline 17 & 0.0164143 & 0.0281311 & 227.478 & 0.0329478 & 11 \\
\hline 18 & 0.0167901 & 0.02952 & 229.628 & 0.0399482 & 12 \\
\hline 19 & 0.0169877 & 0.0296363 & 229.952 & 0.0350164 & 13 \\
\hline 20 & 0.0178438 & 0.0321165 & 231.287 & 0.0365234 & 14 \\
\hline 21 & 0.0189646 & 0.0351948 & 232.883 & 0.034724 & 15 \\
\hline 22 & 0.0191016 & 0.035595 & 232.058 & 0.0423225 & 16 \\
\hline 23 & 0.0180295 & 0.0329751 & 231.548 & 0.0445506 & 17 \\
\hline 24 & 0.0186975 & 0.0340617 & 235.439 & 0.0371163 & 18 \\
\hline 25 & 0.0186553 & 0.034181 & 237.933 & 0.036636 & 19 \\
\hline 26 & 0.0199655 & 0.0376847 & 235.607 & 0.0442152 & 20 \\
\hline 27 & 0.0201641 & 0.0386552 & 236.63 & 0.0433652 & 21 \\
\hline 28 & 0.019439 & 0.0367894 & 236.554 & 0.0432601 & 22 \\
\hline 29 & 0.0203825 & 0.0397589 & 238.043 & 0.0427394 & 23 \\
\hline 30 & 0.0191105 & 0.0363451 & 238.153 & 0.043387 & 24 \\
\hline 31 & 0.0185535 & 0.0348976 & 240.214 & 0.045639 & 25 \\
\hline 32 & 0.0189619 & 0.0352632 & 240.611 & 0.0432701 & 26 \\
\hline 33 & 0.0194353 & 0.036551 & 242.425 & 0.0513595 & 27 \\
\hline 34 & 0.0190076 & 0.0358699 & 245.071 & 0.0472102 & 28 \\
\hline 35 & 0.0193768 & 0.0368544 & 243.855 & 0.0529909 & 29 \\
\hline 36 & 0.0188592 & 0.0357584 & 244.091 & 0.0477801 & 30 \\
\hline 37 & 0.019299 & 0.0374195 & 244.795 & 0.0478752 & 31 \\
\hline 38 & 0.0197707 & 0.039453 & 245.046 & 0.0411248 & 32 \\
\hline 39 & 0.02014 & 0.0397411 & 245.324 & 0.0389477 & 33 \\
\hline
\end{tabular}

\begin{tabular}{|c|c|c|c|c|c|}
\hline 40 & 0.0202459 & 0.0399708 & 246.846 & 0.0381082 & 34 \\
\hline 41 & 0.0208332 & 0.0418801 & 245.93 & 0.041547 & 35 \\
\hline 42 & 0.0197631 & 0.0390435 & 245.945 & 0.045446 & 36 \\
\hline 43 & 0.0213083 & 0.0434407 & 247.991 & 0.0399894 & 37 \\
\hline 44 & 0.0191294 & 0.0370928 & 248.662 & 0.0520261 & 38 \\
\hline 45 & 0.0192423 & 0.0373227 & 248.86 & 0.0474087 & 39 \\
\hline 46 & 0.0206482 & 0.0411038 & 248.45 & 0.0462112 & 40 \\
\hline 47 & 0.0202844 & 0.0402929 & 248.463 & 0.0402691 & 41 \\
\hline 48 & 0.0207255 & 0.0414855 & 249.838 & 0.0465323 & 42 \\
\hline 49 & 0.0202619 & 0.0399072 & 250.208 & 0.0482591 & 43 \\
\hline 50 & 0.0200247 & 0.0388052 & 251.711 & 0.0430924 & 44 \\
\hline 51 & 0.0203567 & 0.0398403 & 251.43 & 0.0418312 & 45 \\
\hline 52 & 0.0205595 & 0.0412424 & 252.115 & 0.0363301 & 46 \\
\hline 53 & 0.0211086 & 0.0427356 & 252.346 & 0.0372035 & 47 \\
\hline 54 & 0.0210721 & 0.0425581 & 253.197 & 0.0330803 & 48 \\
\hline 55 & 0.0196858 & 0.0382482 & 252.23 & 0.0340124 & 49 \\
\hline 56 & 0.0202095 & 0.0398175 & 254.371 & 0.0371822 & 50 \\
\hline
\end{tabular}

Table 1: summary of results for Max_CBR_Dist equations of curves node numbers 7-56

\subsection{Graphical Plots for Results Obtained.}

This analysis is performed in gnuplot in Linux. $\mathrm{x}$-axis distance is in meters.

\section{Node Number 7}

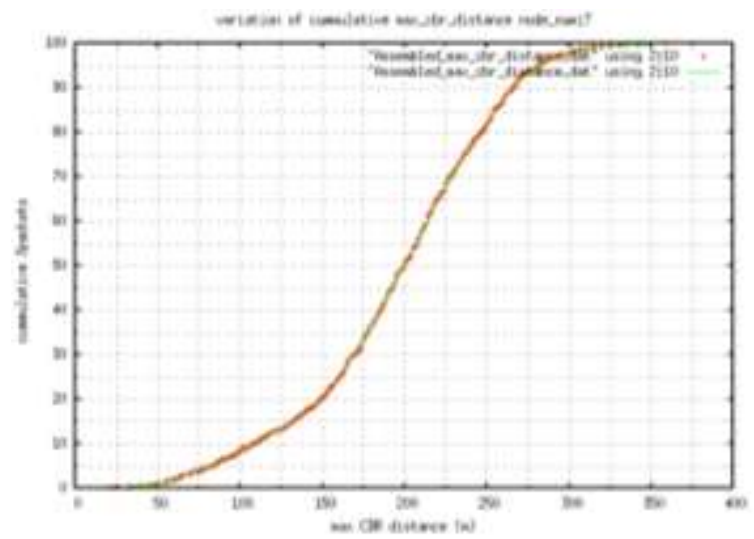

Figure 1(a): cumulative \% CBR against max_CBR_distance : node_number 7

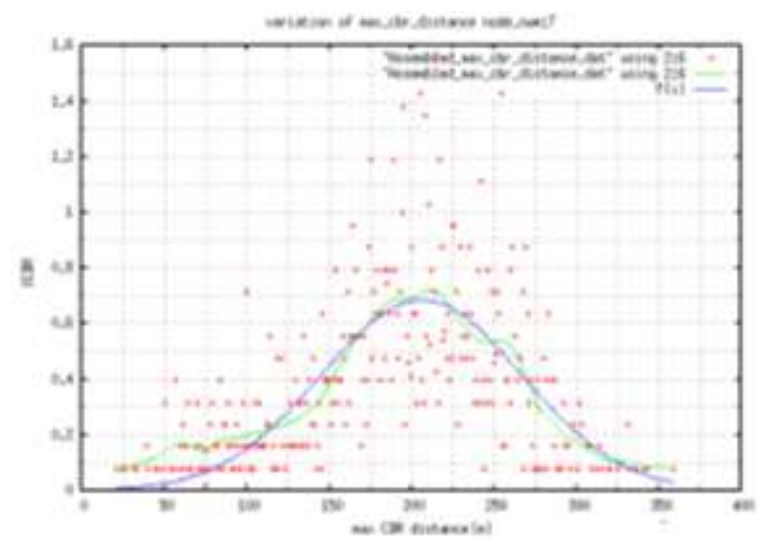

Figure 1(b): \% cbr for Max_CBR_Dist: node_number 7 2. Node Number 8 
Proc. of Sixth International Conference On Advances in Computing, Electronics and Electrical Technology - CEET 2016 Copyright (C) Institute of Research Engineers and Doctors. All rights reserved. ISBN no. 978-1-63248-109-2 doi: 10.15224/ 978-1-63248-109-2-09

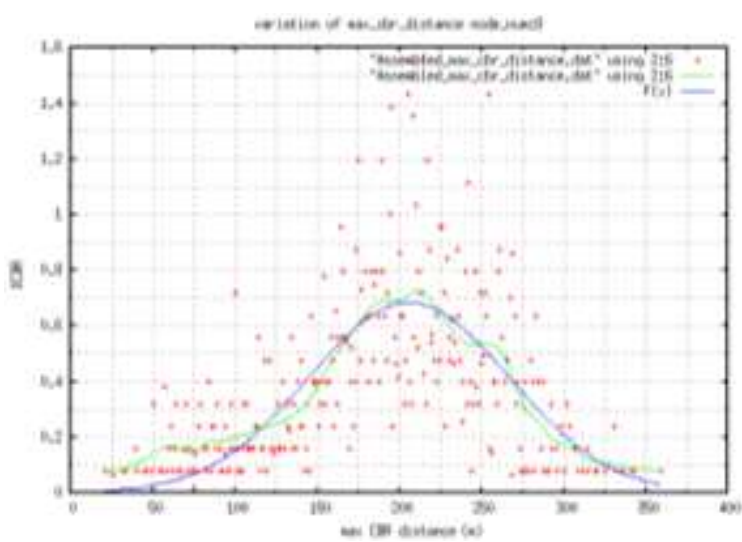

Figure 2: \% cbr for Max_CBR_Dist: node_number 8

3. Node Number 9

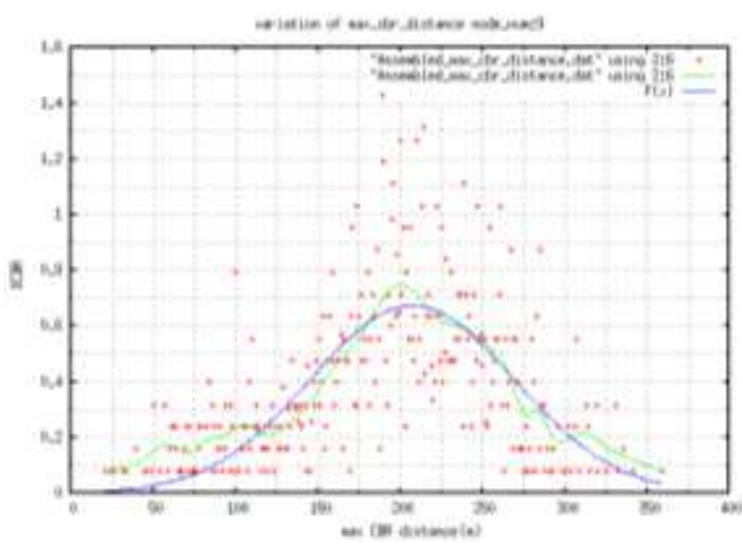

Figure 3: \% cbr for Max_CBR_Dist: node_number 9

4. Node Number 10

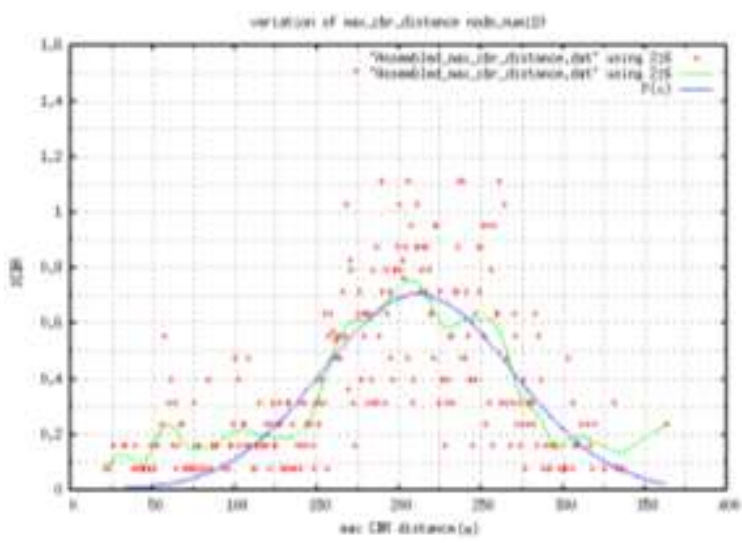

Figure 4: \% cbr for Max_CBR_Dist: node_number 10

5. Node Number 11

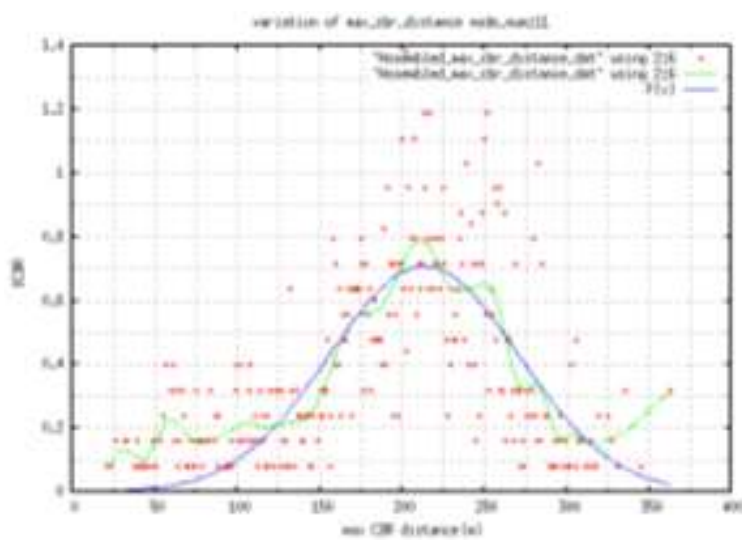

Figure 5: \% cbr for Max_CBR_Dist: node_number 11 6. Node Number 12

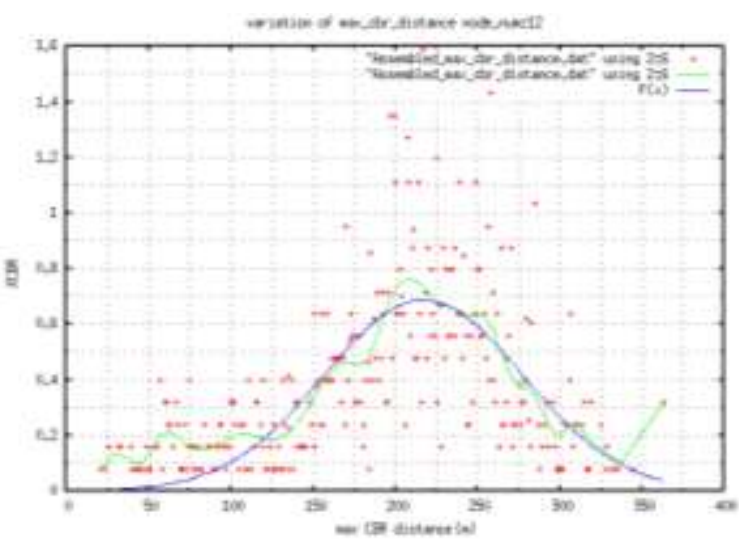

Figure 6: \% cbr for Max_CBR_Dist: node_number 12 7. Node Number 13

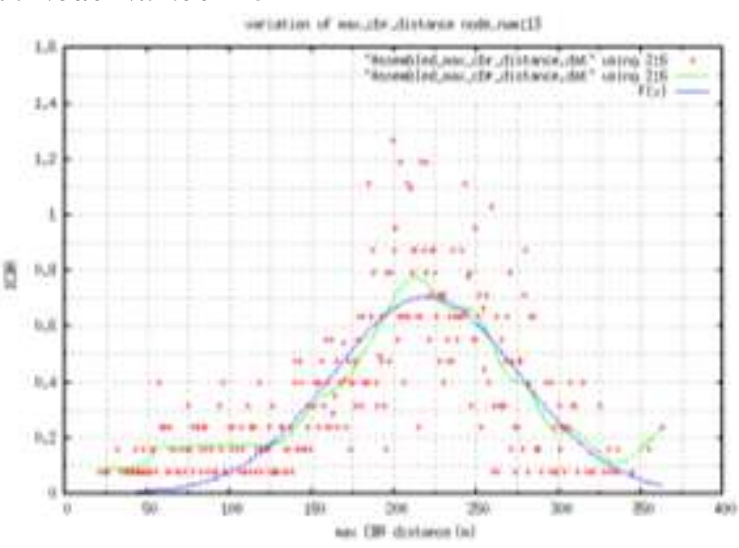

Figure 7: \% cbr for Max_CBR_Dist: node_number 13 8. Node Number 14

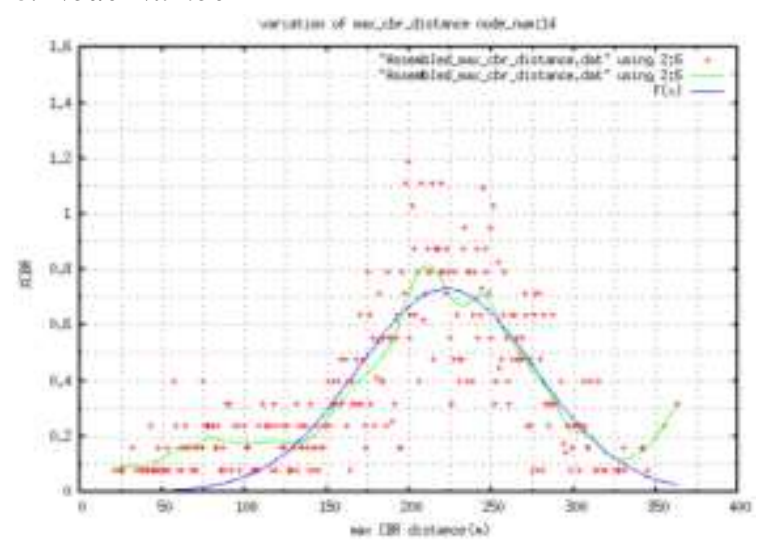

Figure 8: \% cbr for Max_CBR_Dist: node_number 14 9. Node Number 15

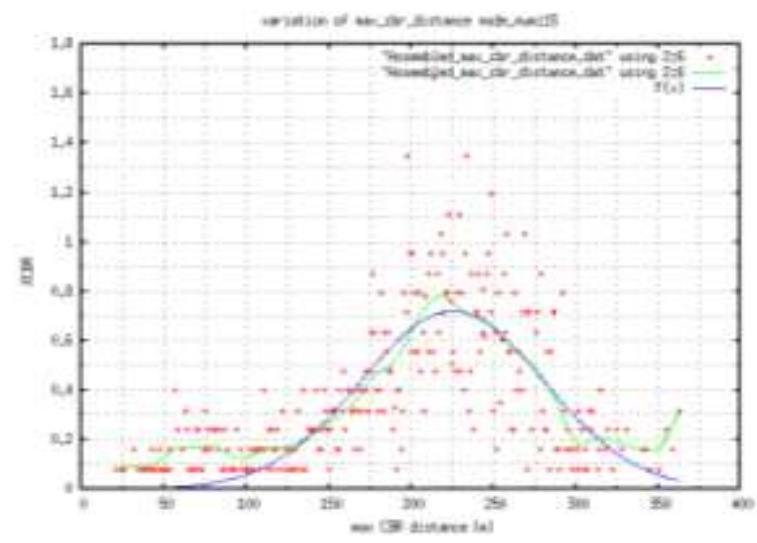

Figure 9: \% cbr for Max_CBR_Dist: node_number 15 10. Node Number 16 
Proc. of Sixth International Conference On Advances in Computing, Electronics and Electrical Technology - CEET 2016 Copyright (C) Institute of Research Engineers and Doctors. All rights reserved. ISBN no. 978-1-63248-109-2 doi: 10.15224/ 978-1-63248-109-2-09

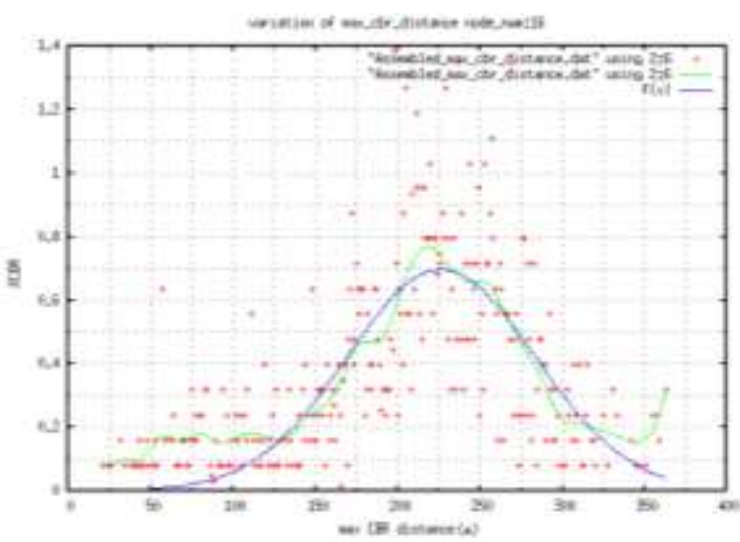

Figure 10: \% cbr for Max_CBR_Dist: node_number 16 11. Node Number 17

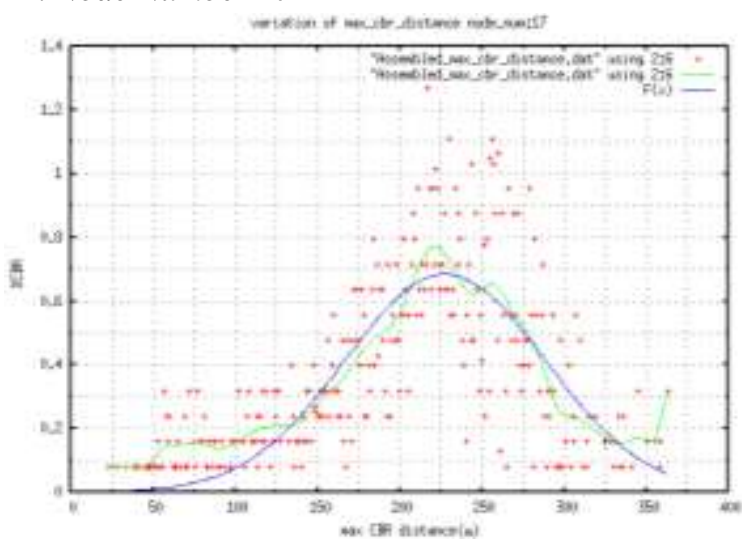

Figure 11: \% cbr for Max_CBR_Dist: node_number 17 12. Node Number 18

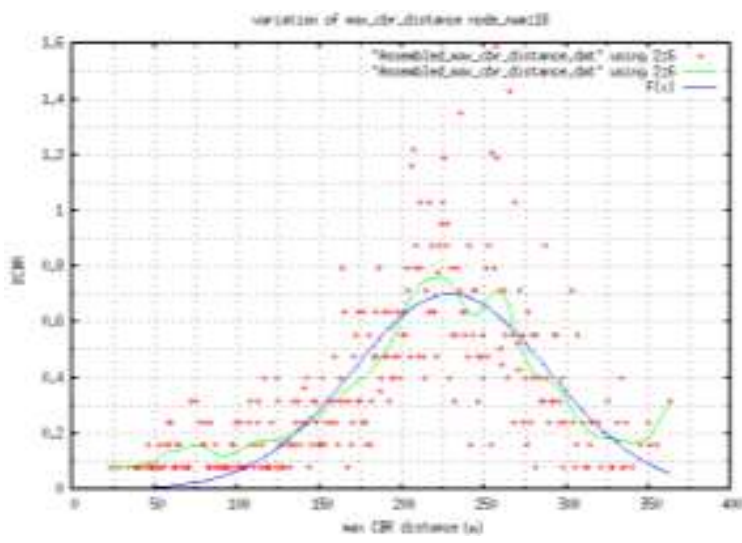

Figure 12: \% cbr for Max_CBR_Dist: node_number 18 13. Node Number 19

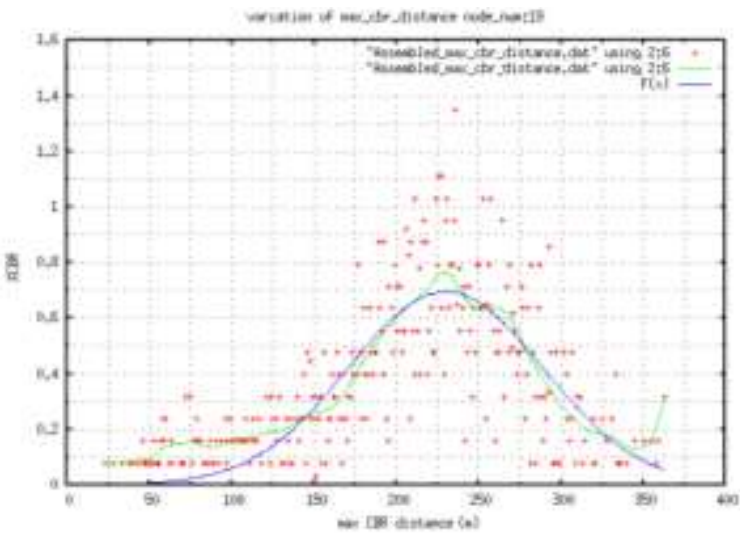

Figure 13: \% cbr for Max_CBR_Dist: node_number 19 14. Node Number 20

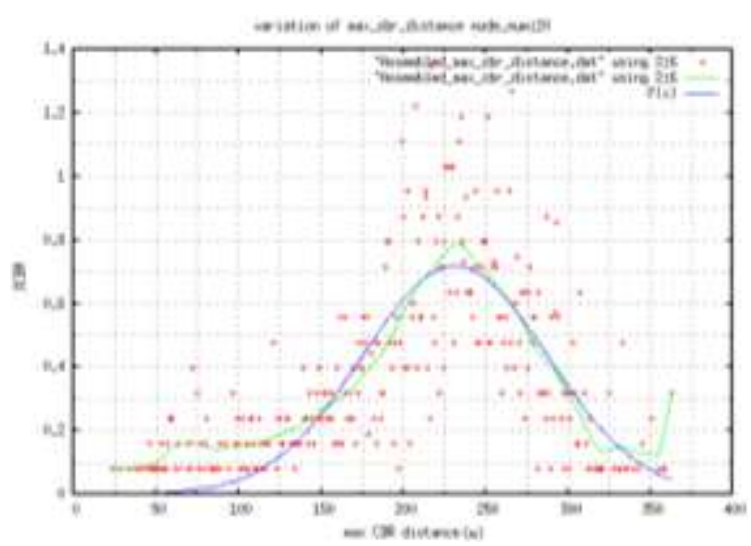

Figure 14: \% cbr for Max_CBR_Dist: node_number 20 15. Node Number 21

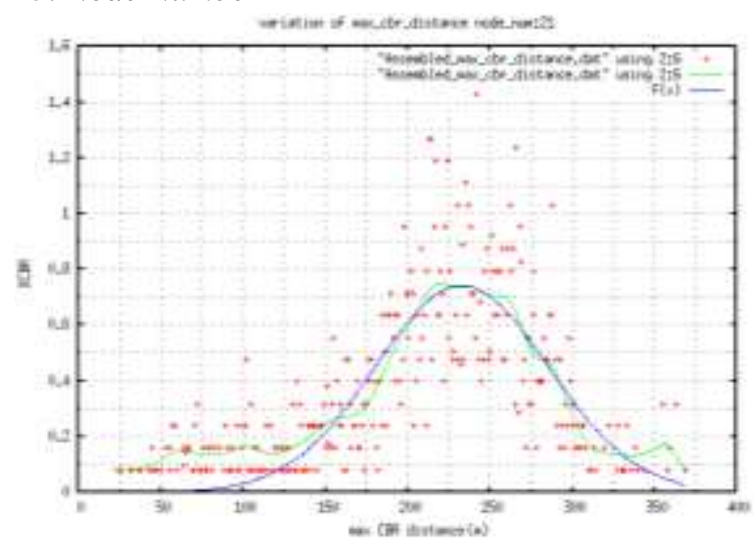

Figure 15: \% cbr for Max_CBR_Dist: node_number 21 16. Node Number 22

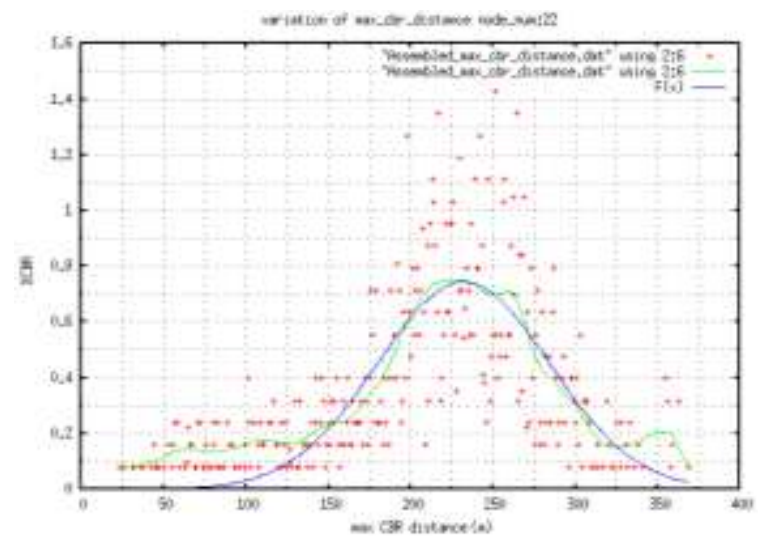

Figure 16: \% cbr for Max_CBR_Dist: node_number 22 17. Node Number 23

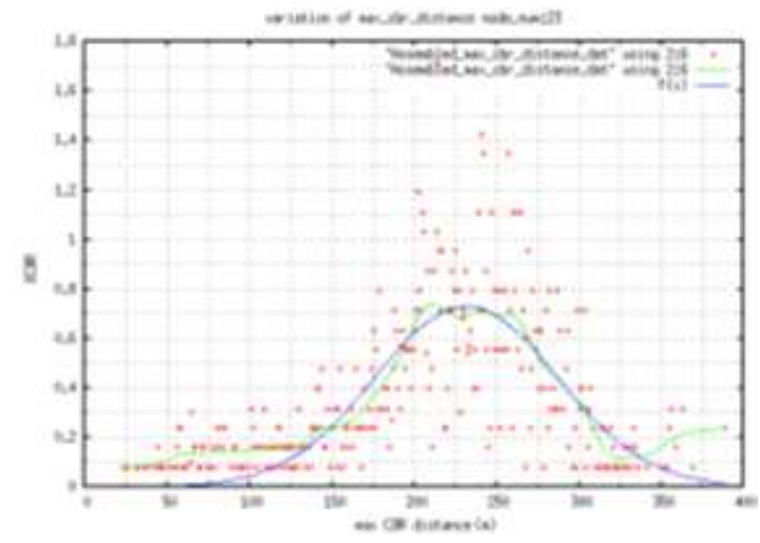

Figure 17: \% cbr for Max_CBR_Dist: node_number 23 18. Node Number 24 
Proc. of Sixth International Conference On Advances in Computing, Electronics and Electrical Technology - CEET 2016 Copyright (C) Institute of Research Engineers and Doctors. All rights reserved.

ISBN no. 978-1-63248-109-2 doi: 10.15224/ 978-1-63248-109-2-09

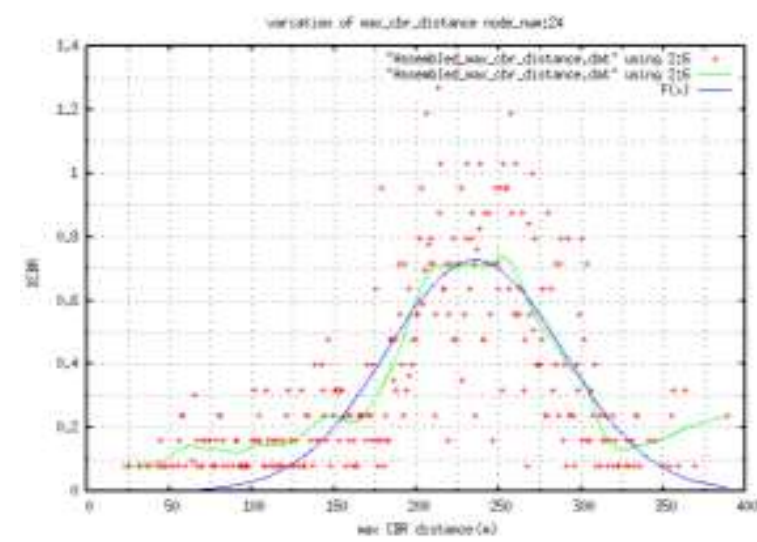

Figure 18: \% cbr for Max_CBR_Dist: node_number 24 19. Node Number 25

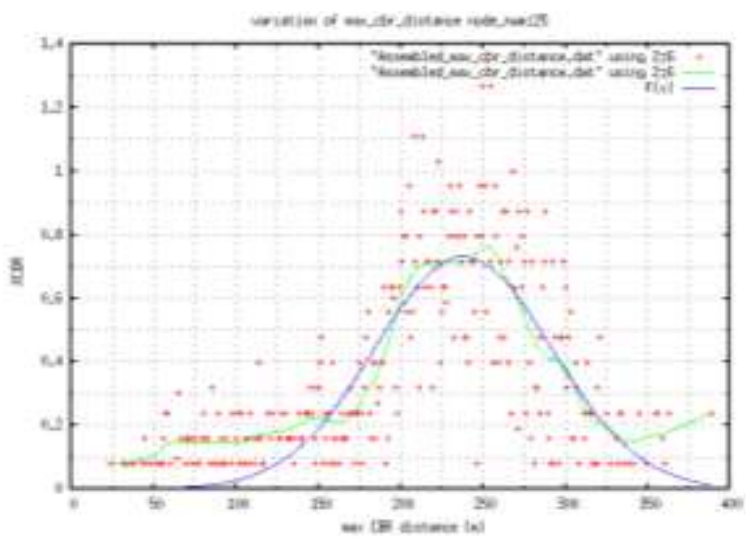

Figure 19: \% cbr for Max_CBR_Dist: node_number 25 20. Node Number 26

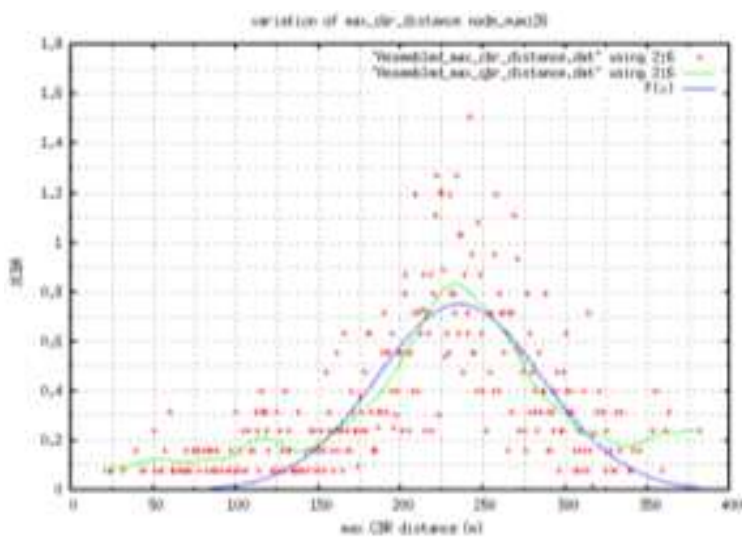

Figure 20: \% cbr for Max_CBR_Dist: node_number 26 21. Node Number 27

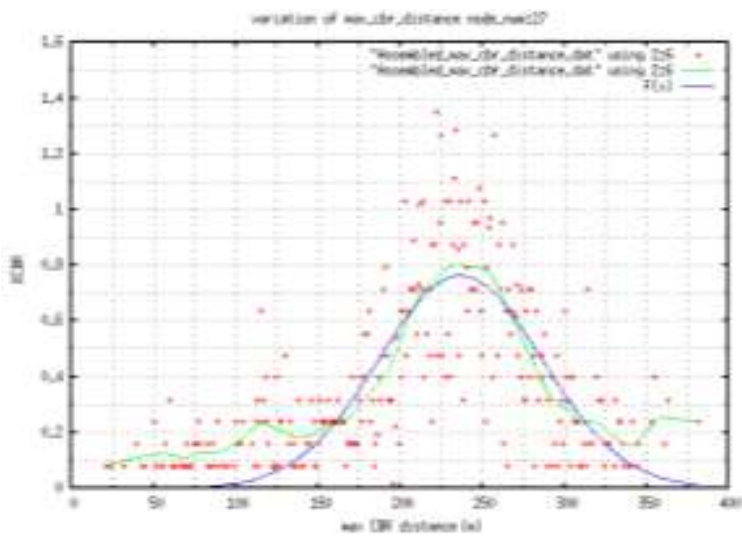

Figure 21: \% cbr for Max_CBR_Dist: node_number 27 22. Node Number 28

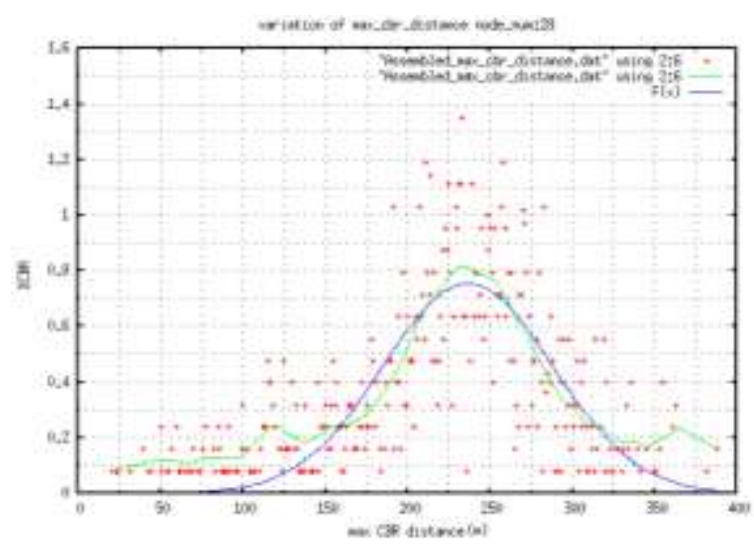

Figure 22: \% cbr for Max_CBR_Dist: node_number 28 23. Node Number 29

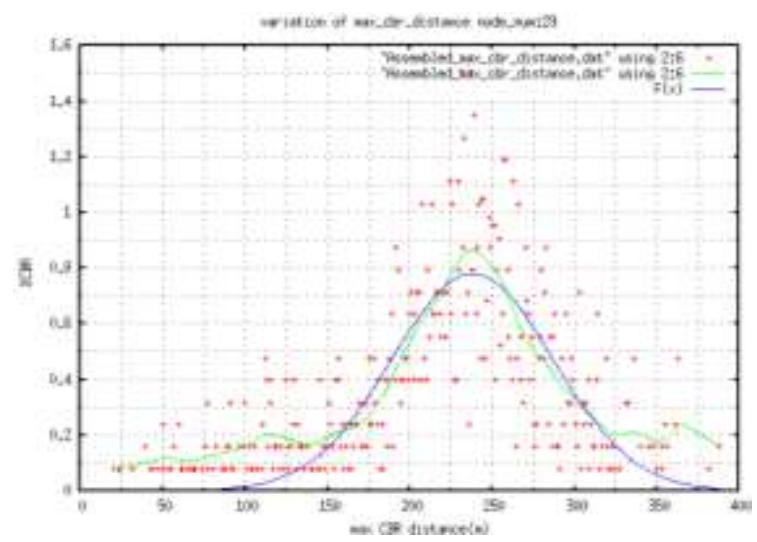

Figure 23: \% cbr for Max_CBR_Dist: node_number 29 24. Node Number 30

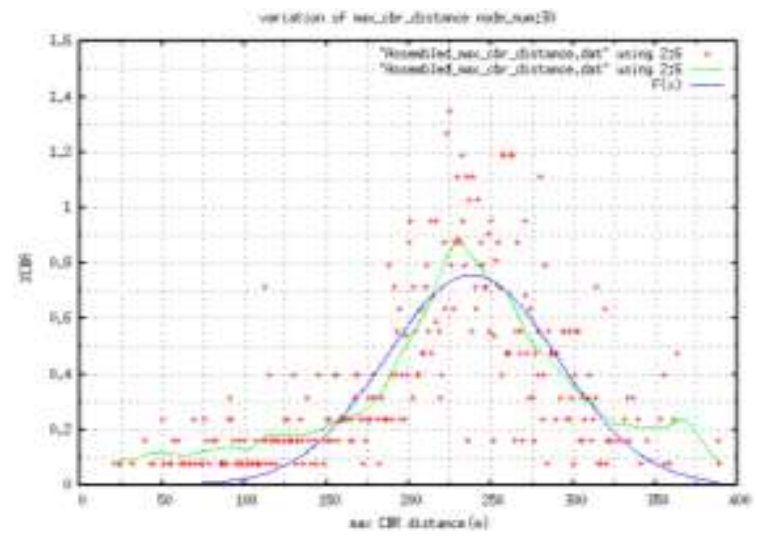

Figure 24: \% cbr for Max_CBR_Dist: node_number 30 25. Node Number 31

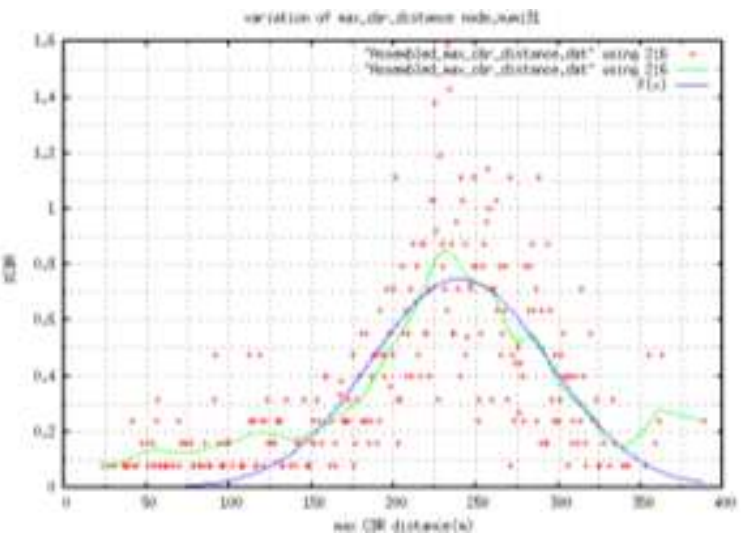

Figure 25: \% cbr for Max_CBR_Dist: node_number 31 26. Node Number 32 
Proc. of Sixth International Conference On Advances in Computing, Electronics and Electrical Technology - CEET 2016 Copyright (C) Institute of Research Engineers and Doctors. All rights reserved.

ISBN no. 978-1-63248-109-2 doi: 10.15224/ 978-1-63248-109-2-09

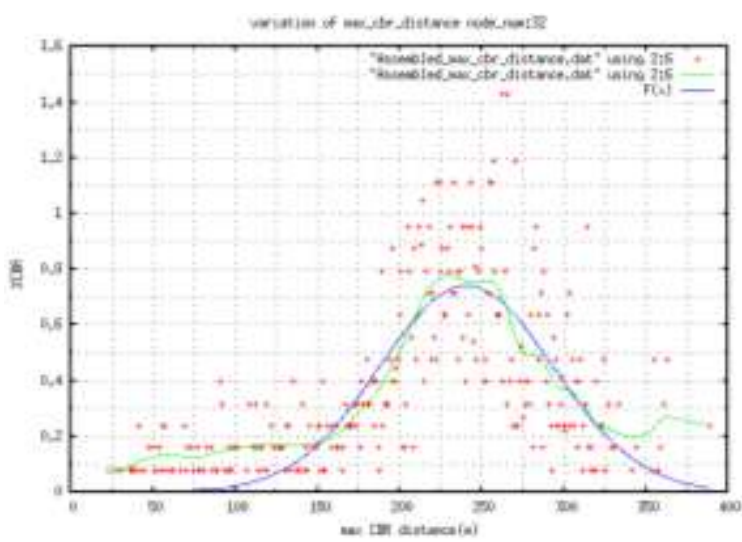

Figure 26: \% cbr for Max_CBR_Dist: node_number 32 27. Node Number 33

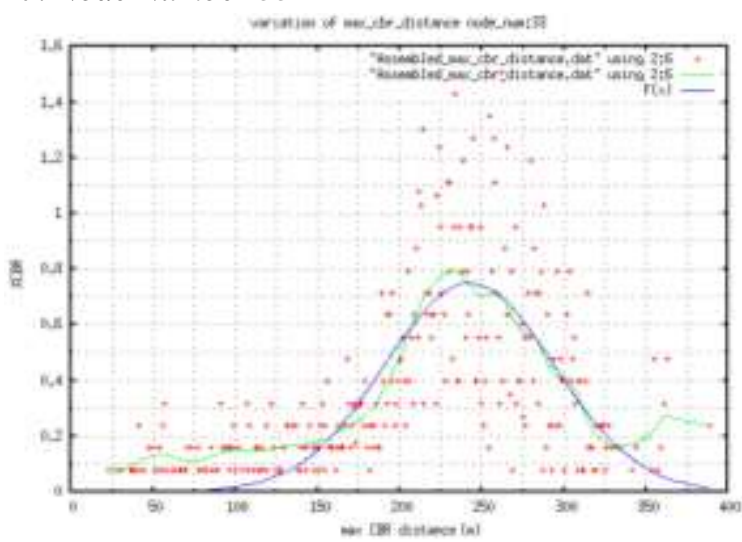

Figure 27: \% cbr for Max_CBR_Dist: node_number 33 28. Node Number 34

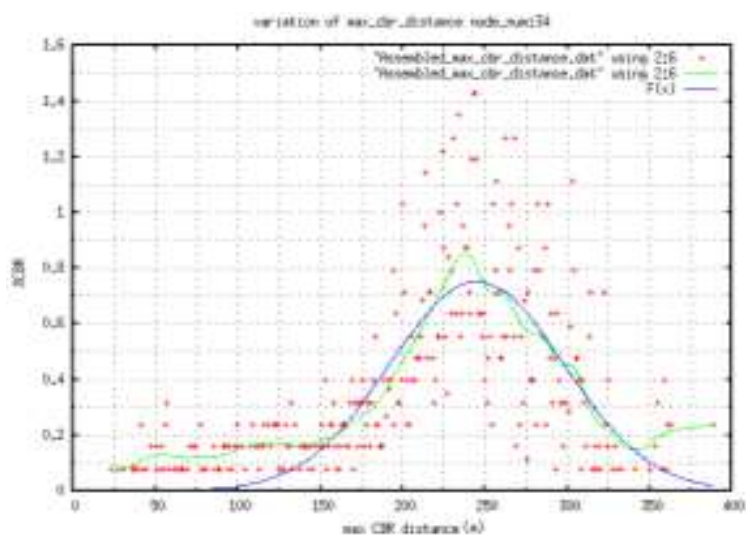

Figure 28: \% cbr for Max_CBR_Dist: node_number 34 29. Node Number 35

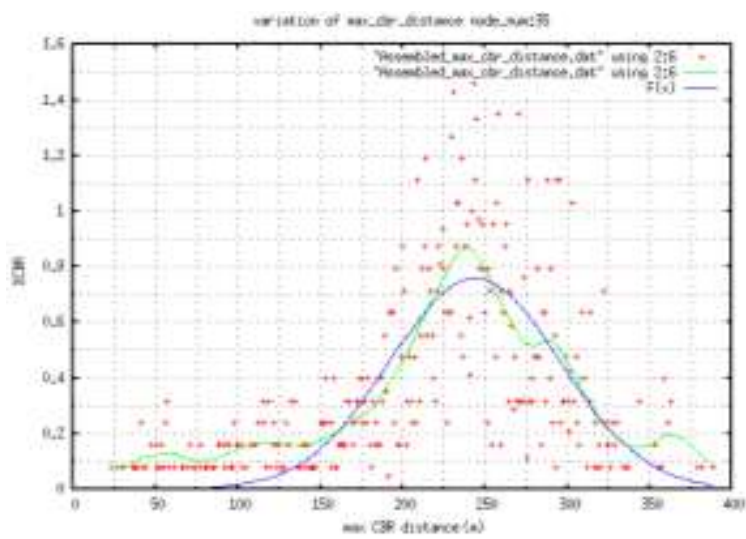

Figure 29: \% cbr for Max_CBR_Dist: node_number 35 30. Node Number 36

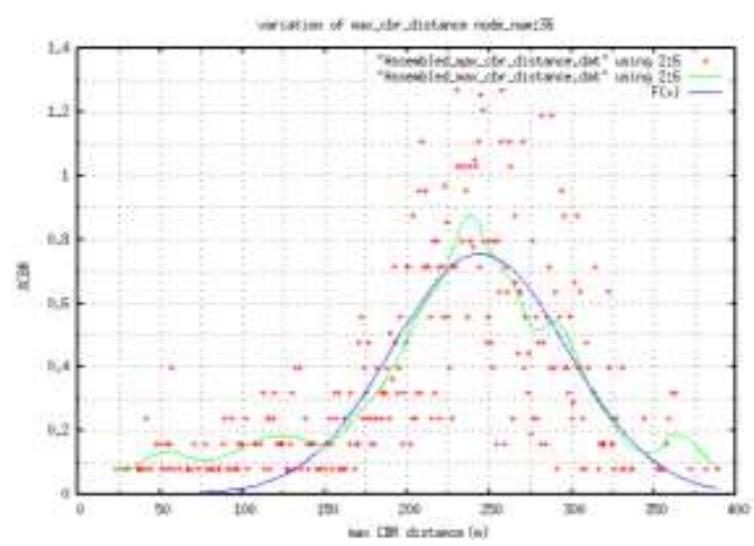

Figure 30: \% cbr for Max_CBR_Dist: node_number 36 31. Node Number 37

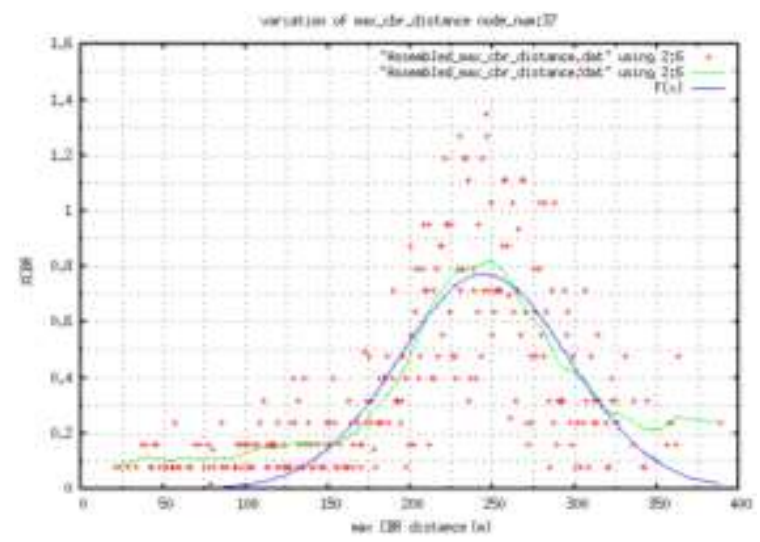

Figure 31: \% cbr for Max_CBR_Dist: node_number 37 32. Node Number 38

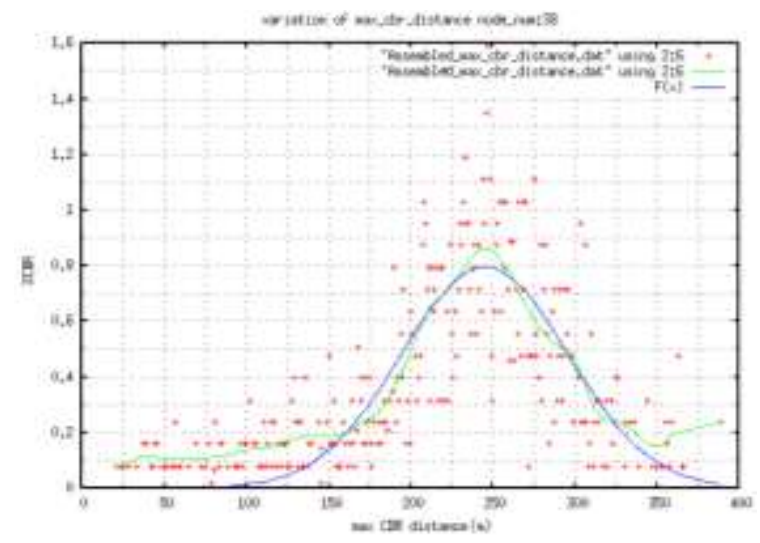

Figure 32: \% cbr for Max_CBR_Dist: node_number 38 33. Node Number 39

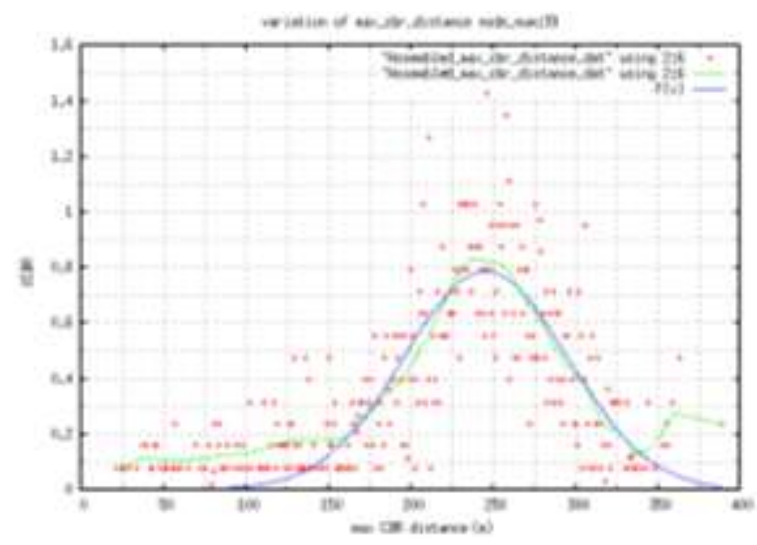

Figure 33: \% cbr for Max_CBR_Dist: node_number 39 34. Node Number 40 
Proc. of Sixth International Conference On Advances in Computing, Electronics and Electrical Technology - CEET 2016 Copyright (C) Institute of Research Engineers and Doctors. All rights reserved.

ISBN no. 978-1-63248-109-2 doi: 10.15224/ 978-1-63248-109-2-09

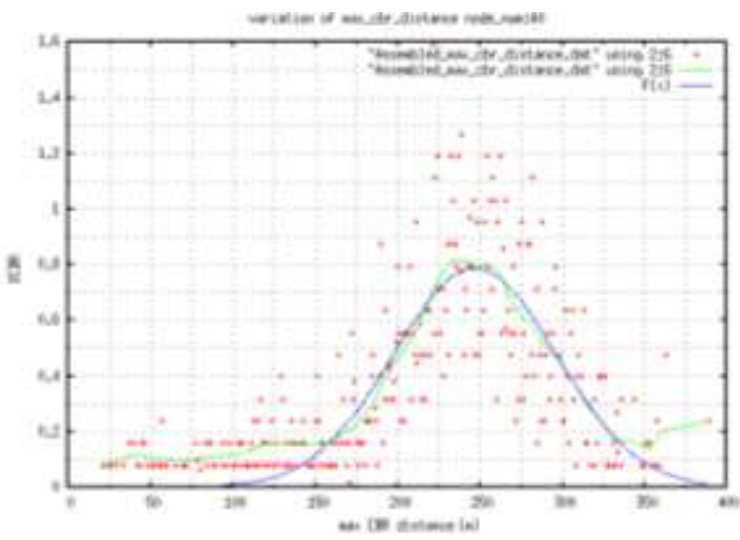

Figure 34: \% cbr for Max_CBR_Dist: node_number 40 35. Node Number 41

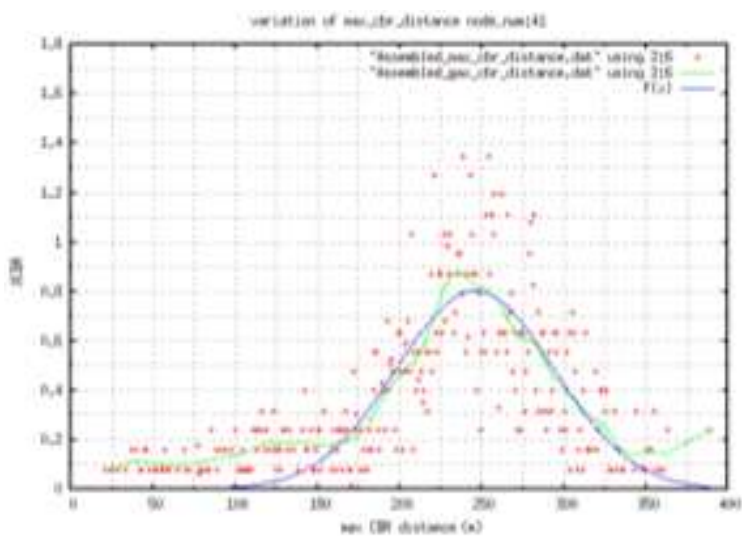

Figure 35: \% cbr for Max_CBR_Dist: node_number 41 36. Node Number 42

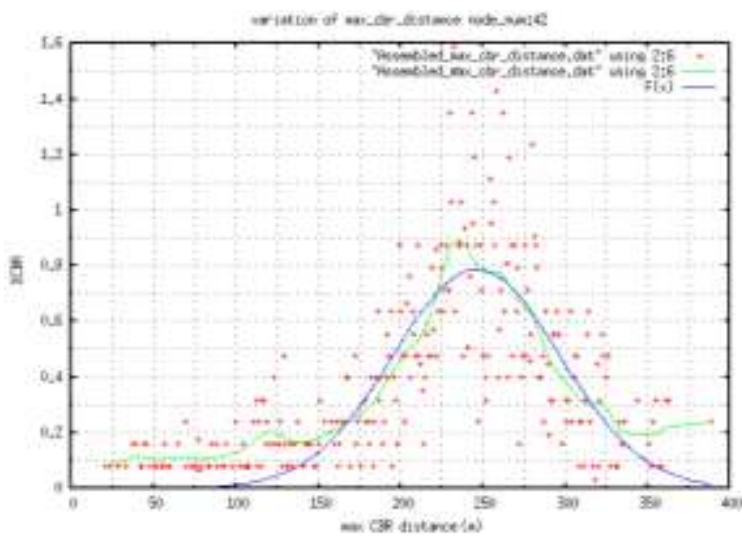

Figure 36: \% cbr for Max_CBR_Dist: node_number 42 37. Node Number 43

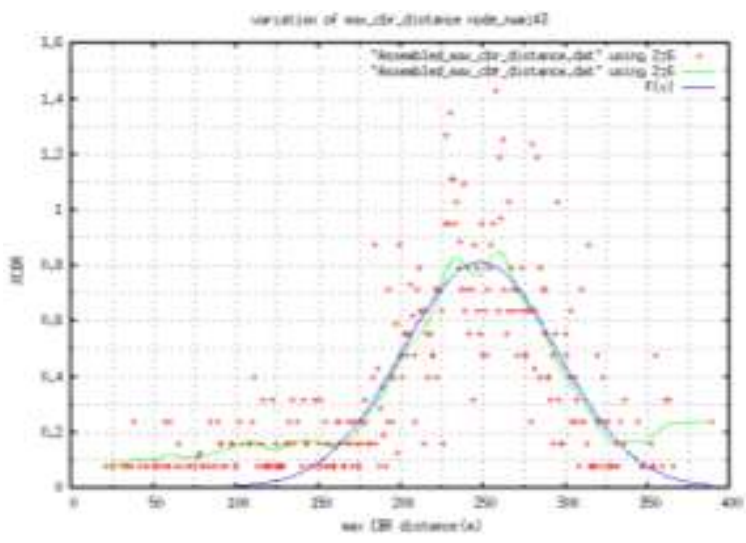

Figure 37: \% cbr for Max_CBR_Dist: node_number 43 38. Node Number 44

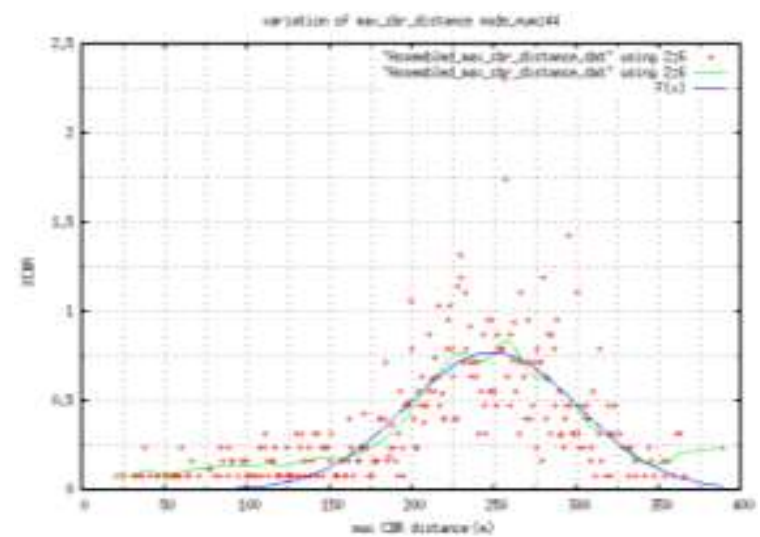

Figure 38: \% cbr for Max_CBR_Dist: node_number 44 39. Node Number 45

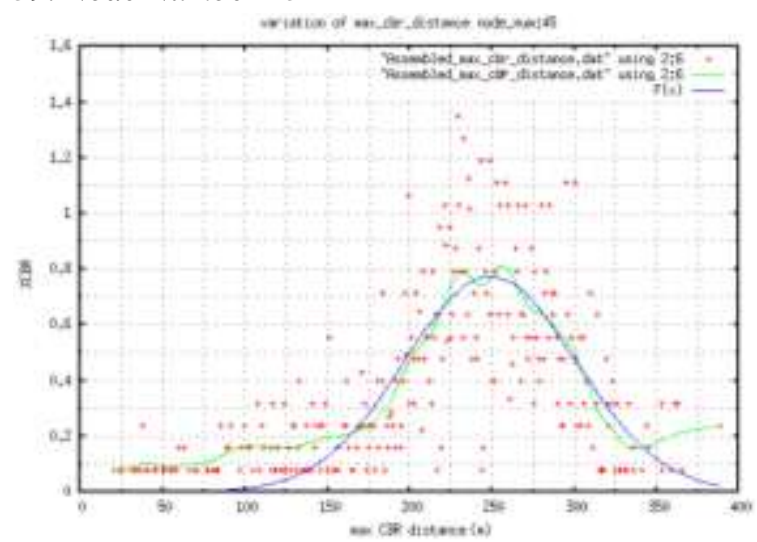

Figure 39: \% cbr for Max_CBR_Dist: node_number 45 40. Node Number 46

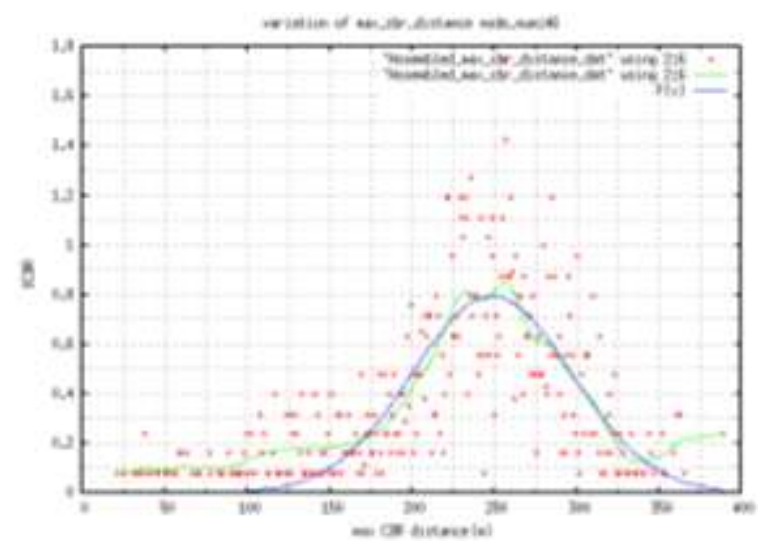

Figure 40: \% cbr for Max_CBR_Dist: node_number 46 41. Node Number 47

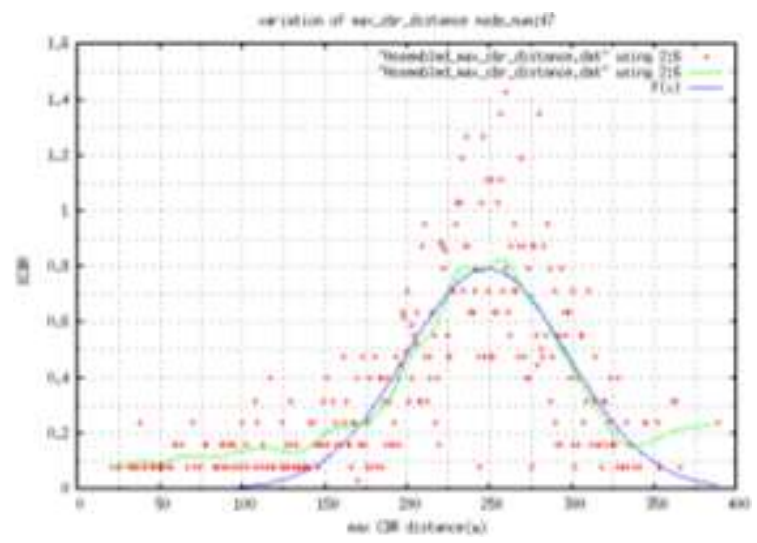

Figure 41: \% cbr for Max_CBR_Dist: node_number 47 42. Node Number 48 
Proc. of Sixth International Conference On Advances in Computing, Electronics and Electrical Technology - CEET 2016 Copyright (C) Institute of Research Engineers and Doctors. All rights reserved.

ISBN no. 978-1-63248-109-2 doi: 10.15224/ 978-1-63248-109-2-09

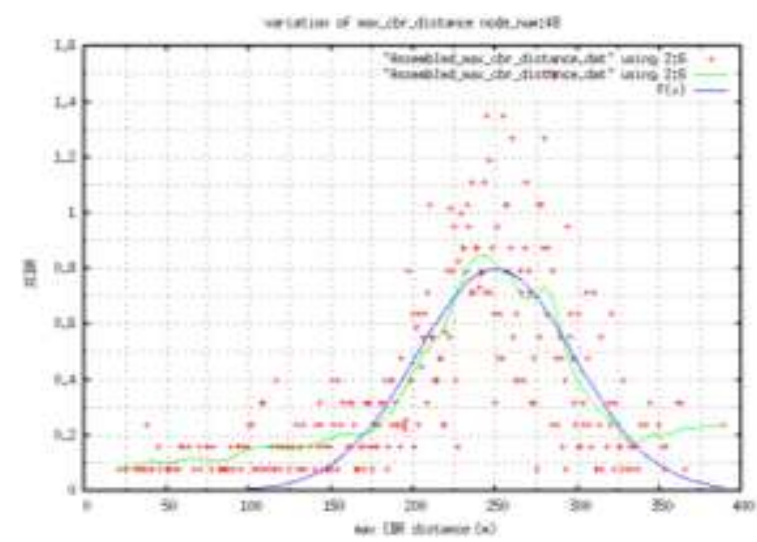

Figure 42: \% cbr for Max_CBR_Dist: node_number 48 43. Node Number 49

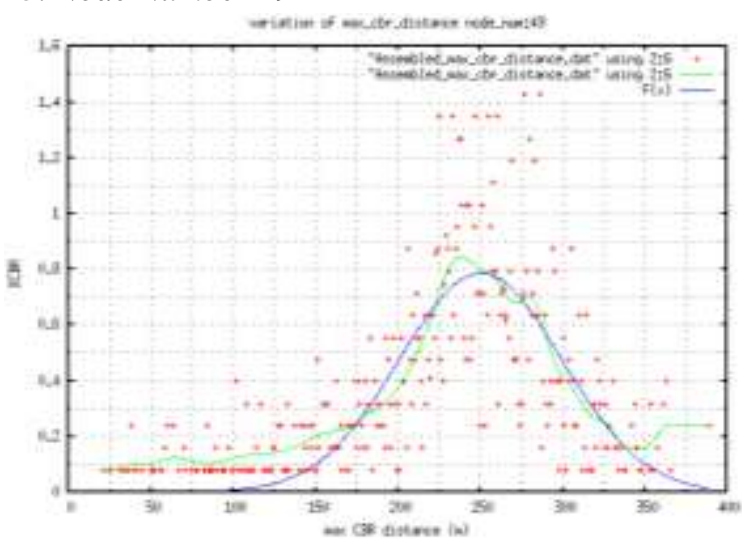

Figure 43: \% cbr for Max_CBR_Dist: node_number 49 44. Node Number 50

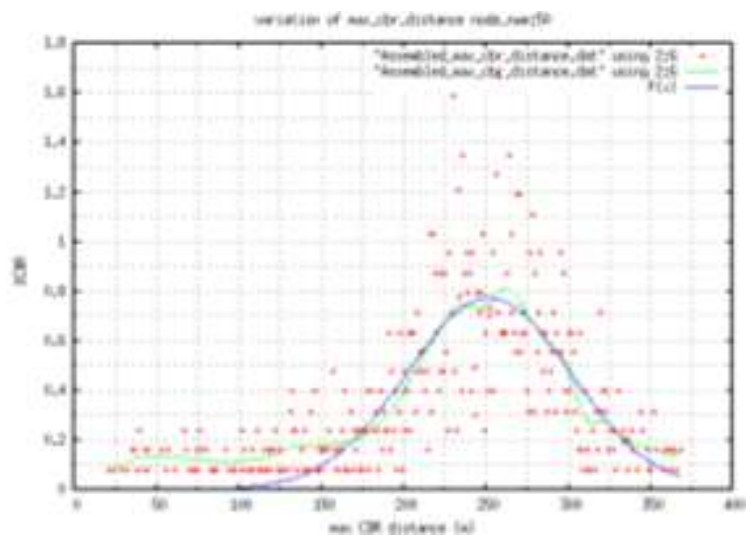

Figure 44: \% cbr for Max_CBR_Dist: node_number 50 45. Node Number 51

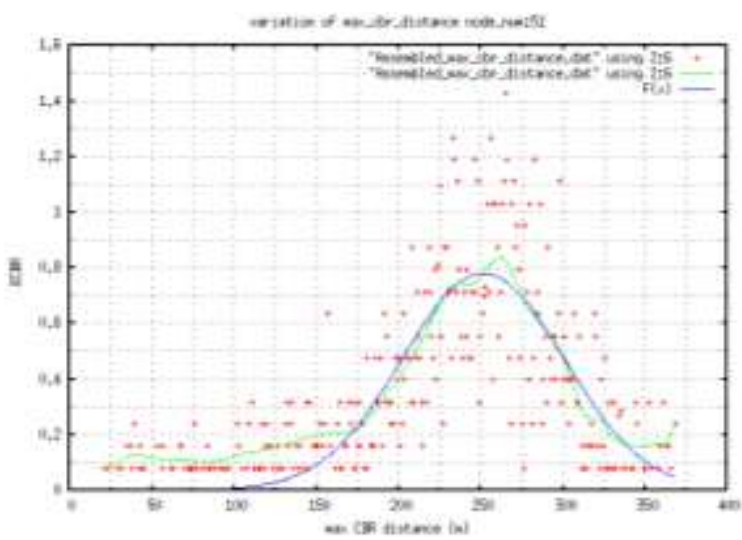

Figure 45: \% cbr for Max_CBR_Dist: node_number 51 46. Node Number 52

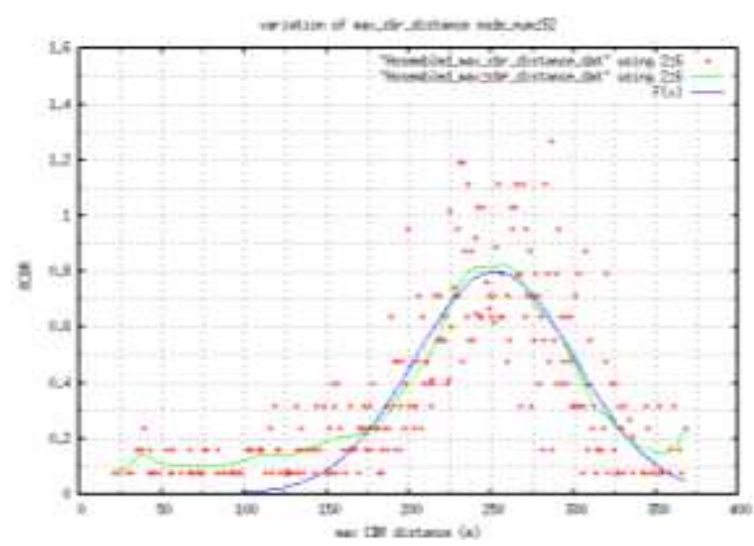

Figure 46: \% cbr for Max_CBR_Dist: node_number 52 47. Node Number 53

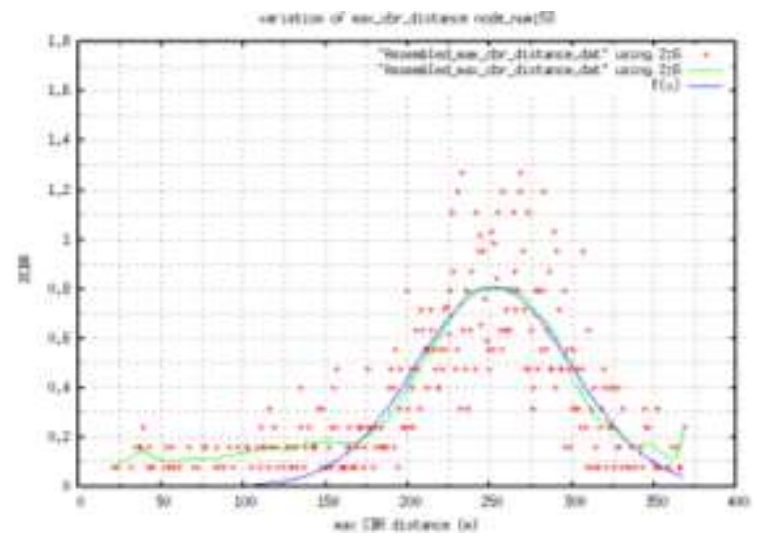

Figure 47: \% cbr for Max_CBR_Dist: node_number 53 48. Node Number 54

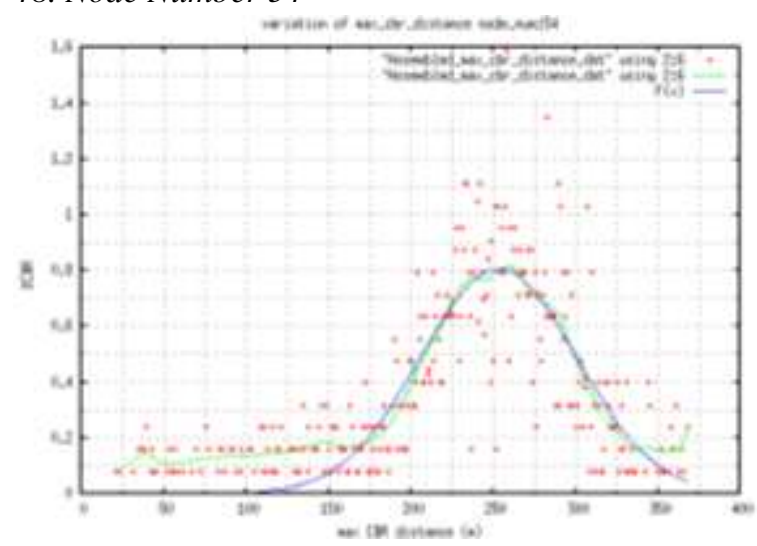

Figure 48: \% cbr for Max_CBR_Dist: node_number 54 49. Node Number 55

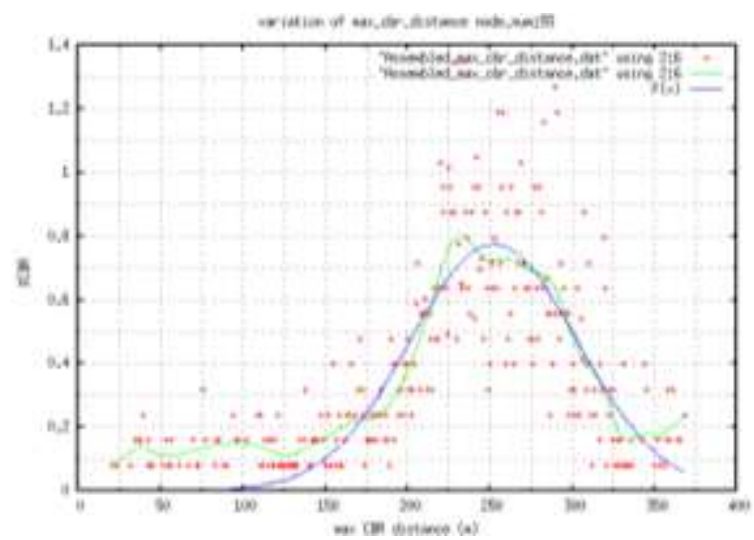

Figure 49: \% cbr for Max_CBR_Dist: node_number 55 50. Node Number 56 


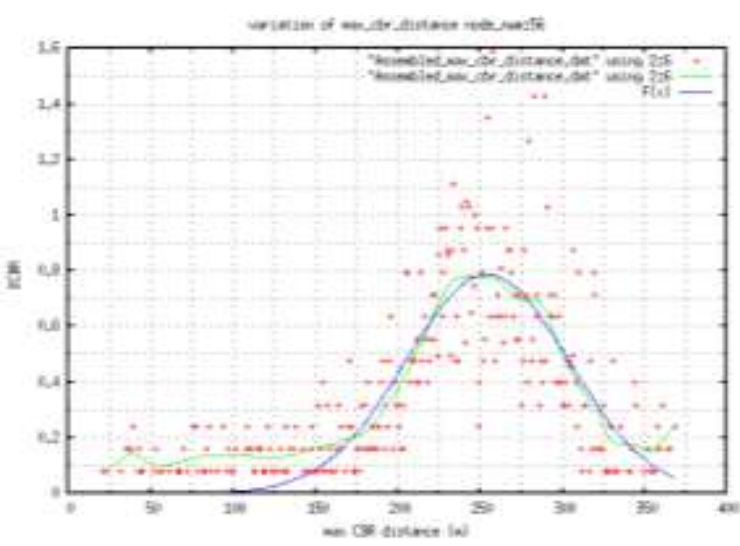

Figure 50: \% cbr for Max_CBR_Dist: node_number 56

\section{Conclusion.}

This piece of research was aimed at studying a facet of distance coverage, rounded to nearest meter, by packets in ubicomp in situation of MANET transmission over varying Node densities. This work extends from a previous work [26].

More precisely here, a metric Max_CBR_Dist, to assess the trend of maximum hop distance by packets in a ubicomp topography with varying node densities, is developed. The experimental results presented here remain empirical based. The model put forward is the normal distribution model.

The assumptions stated in previous paper [21] hold, e.g availability of lightweight algorithms for locationaware transmission in mobile environments, lightweight MAUC OS supports for efficient binding/unbinding of MANET nodes and appropriate multi-threading/parallel communication in modules of MANET nodes.

The further work identified may include: trend analyses of parameters of equations for the model, formulating methods of predictability for metric Max_CBR_Dist and its trend and reporting observations of certain critical values identified. The purposes of this metric is also open for refinement together with its applicability in MANET transmission protocols. Development of further sub-component metrics for metric PPD remain desirable.

\section{References}

[1] M. Kaleem GALAMALI, Assoc. Prof Nawaz MOHAMUDALLY, Towards Dependable Pervasive Systems-A Position and Vision Paper, CEET 2014

[2] M. Kaleem GALAMALI, Assoc. Prof Nawaz MOHAMUDALLY, Model of Energy Savings achievable with Location-aware Node-to-Node Transmission in UbiComp , CEET 2014

[3] M. Kaleem GALAMALI, Assoc. Prof Nawaz MOHAMUDALLY, Model of Energy Savings achievable with Location-aware Node-to-Node Transmission in UbiComp Using Location Refresh Intervals, CEET 2014

[4] M. Kaleem GALAMALI, Assoc. Prof Nawaz MOHAMUDALLY, Model of Energy Savings achievable with Location-aware Transmission in UbiComp Using Relays, CEET 2014

[5] M. Kaleem GALAMALI, Assoc. Prof Nawaz MOHAMUDALLY, Mathematical modeling of need of exact number of relays to ensure seamless mobility in mobile computing, CEET 2014

[6] M. Kaleem GALAMALI, Assoc. Prof Nawaz MOHAMUDALLY, Modelling of need for multiple relays for ensuring seamless mobility, CEET 2014

[7] M. Kaleem GALAMALI, Assoc. Prof Nawaz MOHAMUDALLY, Investigation of prominence of placements of relays in a ubicomp topography,

[8] M. Kaleem GALAMALI, Assoc. Prof Nawaz MOHAMUDALLY, Model of energy savings achievable with location-aware transmission in ubicomp using optimised number of relays.

[9] M. Kaleem GALAMALI, Assoc. Prof Nawaz MOHAMUDALLY, Investigation of Prominence of Placements of Optimised Number of Relays in a Ubicomp Topography using Location-Aware Transmission, CEET 2015

[10] M. Kaleem GALAMALI, Assoc. Prof Nawaz MOHAMUDALLY, Extending Node Battery Availability in Ubicomp with Location-Aware Transmission, CEET 2015.

[11] M. Kaleem GALAMALI, Assoc. Prof Nawaz MOHAMUDALLY, Extending Node Battery Availability in Ubicomp with Location-Aware Transmission using Location Refresh Intervals, CEET 2015.

[12] M. Kaleem GALAMALI, Assoc. Prof Nawaz MOHAMUDALLY, Extending Node Battery Availability in Ubicomp with Location-Aware Transmission using Uniformly Placed Relays, CEET 2015.

[13] M. Kaleem GALAMALI, Assoc. Prof Nawaz MOHAMUDALLY, Extending Node Battery Availability in Ubicomp with Location-Aware Transmission Using Optimally Placed Relays, CEET 2015.

[14] M. Kaleem GALAMALI, Assoc. Prof Nawaz MOHAMUDALLY, Model of Sender Node Energy Savings Achievable with Location-Aware MANET Transmission in Ubicomp. ACCN 2016

[15] M. Kaleem GALAMALI, Assoc. Prof Nawaz MOHAMUDALLY, Model of Overall Node Energy Savings Achievable with Location-Aware MANET Transmission in Ubicomp. ACCN 2016

[16] M. Kaleem GALAMALI, Assoc. Prof Nawaz MOHAMUDALLY, Model of Sender Node Extra Energy Savings Achievable in MANET Against Direct Node-toNode Transmission Using Location-Aware Transmission in Ubicomp. ACCN 2016

[17] M. Kaleem GALAMALI, Assoc. Prof Nawaz MOHAMUDALLY, Model of Overall Node Extra Energy Savings Achievable in MANET against Direct Node-toNode Transmission Using Location-Aware Transmission in Ubicomp. ACCN 2016

[18] M. Kaleem GALAMALI, Assoc. Prof Nawaz MOHAMUDALLY, Model of Energy Consumption Ratio Achievable in MANET Using Location-Aware Transmission in Ubicomp. ACCN 2016

[19] M. Kaleem GALAMALI, Assoc. Prof Nawaz MOHAMUDALLY, Model of Minimum Energy Consumption Ratio Achievable in MANET Using LocationAware Transmission in Ubicomp. ACCN 2016

[20] M. Kaleem GALAMALI, Assoc. Prof Nawaz MOHAMUDALLY, Model of Maximum Energy Consumption Ratio Achievable in MANET Using LocationAware Transmission in Ubicomp. ACCN 2016

[21] M. Kaleem GALAMALI, Assoc. Prof Nawaz MOHAMUDALLY, Model of Overall Energy Consumption Fairness Ratio Achievable in MANET Using LocationAware Transmission in Ubicomp. ACCN 2016

[22] M. Kaleem GALAMALI, Assoc. Prof Nawaz MOHAMUDALLY, Model of Overall Energy Consumption Fairness Proportion Achievable in MANET Using Location- 
Aware Transmission for Ubicomp.

[23] M. Kaleem GALAMALI, Assoc. Prof Nawaz MOHAMUDALLY, Model of Minimum Fairness Proportion Achievable in MANET Using Location-Aware Transmission for Ubicomp.

[24] M. Kaleem GALAMALI, Assoc. Prof Nawaz MOHAMUDALLY, Model of Maximum Fairness Proportion Achievable in MANET Using Location-Aware Transmission for Ubicomp.

[25] M. Kaleem GALAMALI, Assoc. Prof Nawaz MOHAMUDALLY, Model of Sender Fairness Proportion Achievable in MANET Using Location-Aware Transmission for Ubicomp.

[26] M. Kaleem GALAMALI, Assoc. Prof Nawaz MOHAMUDALLY, Model of Distance Travelled by packets in MANETs using Location-Aware Transmission for Ubicomp.

[27] Markus Bylund and Zary Segall, Towards seamless mobility with personal servers, 2004

[28] Masugi Inoue, Mikio Hasegawa, Nobuo Ryoki and Hiroyuki Morikawa, Context-Based Seamless Network and Application Control, 2004

[29] Xiang Song, Umakishore Ramachandran, MobiGo: A Middleware for Seamless Mobility, College of Computing Georgia Institute of Technology, Atlanta, GA, USA, August 2007

[30] Budzisz, Ferrús, R., Brunstrom A., Grinnemo, K, Fracchia, R., Galante, G., and Casadevall, F. Towards transport-layer mobility: Evolution of SCTP multihoming, March 2008

[31] Paul Dourish \& Genevieve Bell, Divining a digital future, 2011.

[32] Xiang Song, Seamless Mobility In Ubiquitous Computing Environments, $\mathrm{PhD}$ Thesis, Georgia Institute of Technology, August 2008

[33] Kevin O Mahony, Jian Liang, Kieran Delaney, User-Centric Personalization and Autonomous Reconfiguration Across Ubiquitous Computing Environments, NIMBUS Centre Cork Institute of Technology, Cork, Ireland, UBICOMM 2012

[34] Pablo Vidales, Seamless mobility in 4G systems, Technical Report, University of Cambridge, Computer Laboratory, Number 656, November 2005

[35] João Pedro Sousa and David Garlan, Aura: An Architectural Framework for User Mobility in Ubiquitous Computing Environments, School of Computer Science, Carnegie Mellon University, USA, August 2002

[36] Dennis Lupiana, Ciaran O'Driscoll, Fredrick Mtenzi, Defining Smart Space in the Context of Ubiquitous Computing, Dublin Institute of Technology, Ireland, Special Issue on ICIT 2009 Conference - Web and Agent Systems, 2009

[37] N.S.V.Shet1, Prof.K.Chandrasekaran 2 and Prof. K.C.Shet3, WAP Based Seamless Roaming In Urban Environment with Wise Handoff Technique, International Journal of UbiComp (IJU), Vol.1, No.4, October 2010

[38] Yipeng Yu Dan He Weidong Hua Shijian Li Yu Qi Yueming Wang Gang Pan, FlyingBuddy2: A Braincontrolled Assistant for the Handicapped, Zhejiang University, UbiComp'12, September 5-8, 2012.

[39] Jing Su, James Scott, Pan Hui, Jon Crowcroft, Eyal de Lara Christophe Diot, Ashvin Goel, Meng How Lim, and Eben Upton, Haggle: Seamless Networking for Mobile Applications, 2007

[40] Rui Han, Moustafa M. Ghanem, Li Guo, Yike Guo*, Michelle Osmond, Enabling cost-aware and adaptive elasticity of multi-tier cloud applications, Future Generation Computer Systems, 2012

[41] Byrav Ramamurthy, K. K. Ramakrishnan, Rakesh K. Sinha, Cost and Reliability Considerations in Designing the NextGeneration IP over WDM Backbone Networks, 2012.

[42] Bhavish Aggarwal, Aditya Akella, Ashok Anand, Athula Balachandran, Pushkar Chitnis, Chitra Muthukrishnan, Ram Ramjee and George Varghese, EndRE: An End-System Redundancy Elimination Service for Enterprises, NSDI 2010, San Jose, CA

[43] Ashok Anand, Vyas Sekar and Aditya Akella, SmartRE: An Architecture for Coordinated Network-wide Redundancy Elimination, SIGCOMM 2009, Barcelona, Spain

[44] John Breeden II, "Smart-phone battery life could double - without better batteries", Nov 14, 2012

[45] Andy Boxall, "When will your phone battery last as long as your kindle", December 5, 2012

[46] Imielinski, T. and Navas, J.C. (1999). GPS-based geographic addressing, routing, and resource discovery. Comms. ACM, Vol. 42, No. 4, pp. 86-92.

[47] Hightower, J. and Borriello, G. (2001). Location Systems for Ubiquitous Computing. IEEE Computer, Vol. 34, No. 8, August, pp. 57-66.

[48] Harter, A., Hopper, A., Steggles, P., Ward, A. and Webster, P. (2002). The Anatomy of a Context-Aware Application. Wireless Networks, Vol. 8, No. 2-3, Mar-May, pp. 187-197.

[49] Hightower, J., Brumitt, B. and Borriello, G. (2002). The Location Stack: A Layered Model for Location in Ubiquitous Computing. Proceedings of the 4th IEEE Workshop on Mobile Computing Systems \& Applications (WMCSA 2002), Callicoon, NY, USA, June, pp. 22-28.

[50] Graumann, D., Lara, W., Hightower, J. and Borriello, G. (2003). Real-world implementation of the Location Stack: The Universal Location Framework. Proceedings of the 5th IEEE Workshop on Mobile Computing Systems \& Applications (WMCSA 2003), Monterey, CA, USA, October, pp. 122-128.

[51] Ko, Y., \& Vaidya, N. H. (2000). Location-aided routing (LAR) in mobile ad hoc networks. Wireless Networks, 6(4), 307-321.

[52] Liao, W.-H., Tseng, Y.-C., \& Sheu, J.-P. (2001). GRID: a fully location-aware routing protocol for mobile ad hoc networks. Telecommunication Systems, 18(1), 37-60.

[53] Kuhn, F., Wattenhofer, R., Zhang, Y., \& Zollinger, A. (2003). Geometric ad-hoc routing: of theory and practice. In Proceedings of the ACM (PODC'03) (pp. 63-72).

[54] Jiang, X., \& Camp, T. (2002). Review of geocasting protocols for a mobile ad hoc network. In Proceedings of the Grace Hopper Celebration (GHC).

[55] Ko, Y. \& Vaidya, N. H. (1999). Geocasting in mobile ad hoc networks: location-based multicast algorithms. In Proceedings of the IEEE (WMCSA'99) (pp. 101)

[56] Mauve, M., Fuler, H., Widmer, J., \& Lang, T. (2003) Position-based multicast routing for mobile ad-hoc networks (Technical Report TR-03-004). Department of Computer Science, University of Mannheim.

[57] Xu, Y., Heidemann, J., \& Estrin, D. (2001). Geographyinformed energy conservation for adhoc routing. In Proceedings of the ACM/IEEE (MOBICOM'01) (pp. 70-84).

[58] Hu, Y.-C., Perrig, A., \& Johnson, D. (2003). Packet leashes: a defense against wormhole attacks in wireless ad hoc networks. In Proceedings of the INFOCOM' 03 (pp. 19761986).

[59] Patwari, N., Hero III, A. O., Perkins, M., Correal, N. S., \& O'Dea, R. J. (2003). Relative location estimation in wireless sensor networks. IEEE Transactions on Signal Processing, 51(8), 2137-2148.

[60] Baldauf, M., Dustdar, S., \& Rosenberg, F. (2007). A Survey on Context Aware Systems. International Journal of Ad Hoc and Ubiquitous Computing, Inderscience Publishers. forthcoming. Pre-print from: http://www.vitalab.tuwien.ac.at/ florian/ papers/ijahuc2007.pdf

[61] Hong, D., Chiu, D.K.W., \& Shen, V.Y. (2005) Requirements elicitation for the design of context-aware applications in a ubiquitous environment. In Proceedings of ICEC'05 (pp. 590-596)

[62] Neeraj Tantubay, Dinesh Ratan Gautam and Mukesh Kumar Dhariwal, A Review of Power Conservation in Wireless Mobile Ad hoc Network (MANET)", International Journal of computer Science Issues, Vol 8, Issue 4, No 1, July 2011.

[63] Wenrui Zhao, Mostafa Ammar and Ellen Zegura, "A Message Ferrying Approach for Data Delivery in Sparse 
Proc. of Sixth International Conference On Advances in Computing, Electronics and Electrical Technology - CEET 2016

Copyright (C Institute of Research Engineers and Doctors. All rights reserved.

ISBN no. 978-1-63248-109-2 doi: 10.15224/ 978-1-63248-109-2-09

Mobile Ad Hoc Networks", MobiHoc'04, May 24-26, 2004,

Roppongi, Japan.

About Author (s):

Associate Professor Nawaz Mohamudally works at University of Technology, Mauritius (UTM) and has undertaken supervision of MPhil/PhD Students for many years.

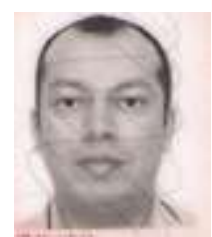

M. Kaleem Galamali is a part-time student (achieved M Phil Transfer on 28.10.2014, currently PhD student) at UTM under supervision of A.P. Nawaz Mohamudally. 